\title{
Fundamental concepts of product/technology/process informational integration for process modelling and process planning
}

\author{
A. Bernard, N. Perry \\ Institut de Recherche en Communication et Cybernétique de Nantes (IRCCyN) \\ UMR CNRS 6597, Nantes, France
}

\begin{abstract}
The aim of this keynote paper is to summarize the main basic concepts for data integration during the product life-cycle. This integration is necessary in order to favor a more efficient communication between actors from inside or outside the company, in a distributed design or e-design context. The information is based on models that structure them and allow reusing them due to the memorization of design history. The current evolutions extend the prospective fields of this approach both to earlier stages (functional aspects, etc...) and to later stages (logistics, recycling, etc...). It remains, in a global vision of the enterprise, many prospective fields that should allow succeeding in the total tracability of product during their life-cycle.
\end{abstract}

\section{Keywords:}

design, production, integration, development of products and systems.

\section{INTRODUCTION}

Product creation time has dramatically decreased mainly due to product versatility and diversity. The main reason is an increasing demand of consumer to use customized products. Consequently, product realization is shortening and companies need new software tools and environments in order to be able to collaborate with various partners that are very often different from one project to an other. Product, technology and process modeling is a base for the informational integration during product life-cycle management. But the efficiency of such an approach depends on the possibility of memorization and re-use of knowledge related to product and realization technologies and processes (from the concepts to the physical industrial objects and environments). The base of knowledge is of course technological based but is also related to management and organizational aspects.

Information and knowledge management is necessary to support such approach. It remains two major difficulties that are the determination of what is the information that has to be memorized and how to represent them in order to provide an efficient re-use. Many of product life-cycle activities are computer-aided, like design, process planning, production scheduling, maintenance, etc... During these stages, the information and knowledge are related to product, its environment (tools, production equipments), its logistics (delivery) and its maintenance (usage history). These activities concern different competences that need many software which use several formats to represent information contents. These contents have to be presented to the users according to their own points of view depending their competences and needs.

In the following are presented some fundamental concepts of product modeling, design process modeling, knowledge-based models related to production processes, and more particularly the link between product, technology and production process [1] [2]. Then, some elements of organizational aspects are delivered before a more prospective part of this paper concerning a topic of interest for many industrial and service fields, a global information system for the individual tracking of products during their complete life-cycle.

\section{PRODUCT MODELS}

The first initiatives and results in the field of information model related to product have been successful about ten to twelve years ago [3]. It seems important to underline some fundamentals on functional, structural and geometrical (physical) points of view of mechanical part and assembly modeling.

\subsection{Functional, Structural, Physical (geometrical) aspects}

At the beginning of 90's, C. Mony proposed a product model based on three essential aspects that :

- the functions that correspond to the requirements,

- the parts and the components of the product,

- the geometry and the physical properties of each of these parts and components [4]. The feature concept ${ }^{1}$ allowed to formalizing both representation, functional and structural properties (accuracy, assembly conditions, etc.). The link with production processes has also been formalized thanks to the feature concept (technological, link, machining, etc.).

Some main ideas have also been highlighted related to future orientations for some extensions and applications of these concepts. In particular, " a function can be realized by one or more features or parts ", " a part or a feature can contribute to the realization of several functions », « in mechanical engineering, a given model is relevant for a given application ", " each point of view needs a particular geometrical model that allows the

\footnotetext{
1 "a parameterized geometric elements group, handled like an object and having a semantics (a mean) compared to one (or several) function(s) of the product engineering. These groups can be associates various attributes and methods allowing an improvement of the geometrical data and the handling of high level semantics objects" [4]
} 
manipulation of the elements strictly indispensable for the realization of its own objectives ", " all the points of view have to be coherent ».

Of course, other significant contributions have followed these precursor works. It has to be mentioned the following results obtained during DEKLARE [5] [6] and MOKA [7] [8] projects, the chromosomal model based on domain theory [9] or the level-based model (objectives, functions, physical structure, parts and assembly) [10].

\subsection{Comportemental aspect}

A behavioral aspect has been introduced in the product models. This is to say all the elements that characterize every law, data, etc., more generally the performance criteria for the evaluation of the coherency of the solutions relatively to functional requirement.

An international well-know initiative, the FBS approach (Function / Behavior / Structure) has supported a new orientation at the beginning of 1990's and has inspired the work of Y. Harani [11]. Equations and variables of behavior have been integrated in a product and process model, joined to a point of view approach. This notion is developed in the following paragraph.

\subsection{Multi-view aspect}

The notion of multi-views has been necessary in order to let the professionals have an access to a unique and integrated product model. This model has to be shared but all the information is not necessary. This is better to have specific semantic and interfaces. On such topic, the work from 3S laboratory has to be highlighted [12] and also those of $\mathrm{K}$. Mawussi who proposed a model integrating the representation of the parts, of the raw parts and forming tools. The different views are related to forging part design, forging die design and manufacturing [13]. Y. Harani has also based her experiments on a multi-view and multi-technological case study : an electric engine.

Of course, these examples represent a very limited part compared to what is needed for the construction and the exploitation of a multi-view product model in an industrial project environment. On a practical point of view, a very important aspect is the construction and the evolution of each point of view and the coherency control of the global product model.

Concerning the first aspect, $\mathrm{O}$. Million has proposed an original approach based on the «bridge feature » concept [14]. Such feature constitutes a transition element that allows connecting a new point of view model to the rest of the model. The space dedicated to the new part of model is limited as an independent structure in order to be able to modify this part of model without any perturbation in the rest of the model.

If one considers the second aspect related to the global coherency of the model, F. Sellini has proposed a method in order to globally control the syntax of the model. In this context, it is also possible to check some incompatible combinations that correspond to mutual exclusions of technological solutions [7] [8].

\subsection{Diversity aspect}

Diversity is also one of the basic concepts that are necessary to be managed mainly due to the customization demand. A typical example is the one of automotive industry. The theoretical number of combinations is particularly large and is relatively wellmastered. In such approach, automotive companies have proposed some significant initiatives for the proposition of standardized representations of automotive products and means used for their design and manufacturing. One can notice a proposition of important concepts in AP STEP 214 by $\mathrm{F}$. Chambolle, concepts integrated by PSA [15]. The figure 1 represents schematically how the diversity and the structure at different levels (part, solution, assembly, function, vehicle) is taken into account in the model. Based on such a structure, some requests related to any kind of data can be expressed in order to favor the search of information and then the process of decision during the different stages of an automotive project. These models constitute the base for data exchange with co-contractors and can serve as a reference for future projects. They contain both technical and organizational information that represent the links between the automotive product itself and what has to be necessarily used during a vehicle life-cycle.

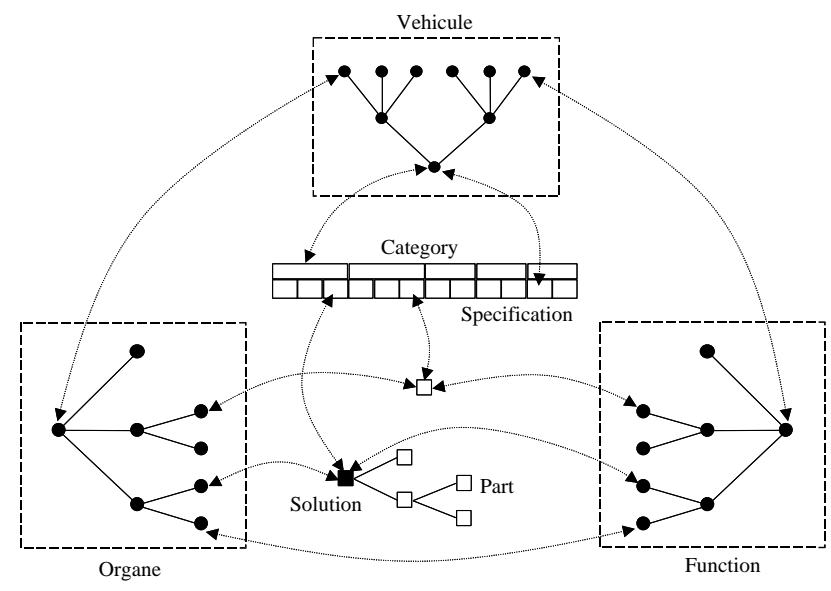

Figure 1 : representation of the basic concepts structuring the model [15]

\section{LINK BETWEEN PRODUCT AND TECHNOLOGY}

Product models have to represent efficiently the information needed by the product life-cycle. This implies a better use of CAD environments and also a more efficient capability for the memorization and the transmission of numerical data. But, according to common opinion, a real advantage is depending on the integration of the information related to the product definition with the information characterizing the production technologies and processes.

\subsection{Technical aspect}

This coherent integration has been improved thanks to the results of several works, in particular those of $F$. Villeneuve [16] then the ones of J. Ben Younès [17]. He has proposed an approach for the integration of both the product (based on features used to describe the shapes of the part, including the properties wanted for the determination of machining capabilities as accessibility, tolerances, etc.), the cutting tools necessary for machining each shape on the part (feature), and strategies characterizing the possibilities of related movement between the tool and the part (sequence). The main result of this work is the TSG concept (ToolSequence-Geometry) that allows the specification of the knowledge related to the machining of shapes on a part (Figure 2). This figure presents a partial view of the conceptual model, which shows the links between the TSG concepts and the data necessary for a machining process generation.

Thanks to these elements, it is possible to specify knowledge related to a particular skill but this is not 
sufficient enough to support the complete loop (from the specification and the choice of the process to the effective realization of the product using the chosen process). A significant contribution for such possibility is the difference concept proposed by S. Magnet-Canet [18]. This difference is evaluated between a theoretical definition of the perfect technology and the representation of the real physical technology effectively used for the manufacturing of the part. This model, associated to a process planning functionality is able to deliver a first comparative evaluation between the technologies mastered by the company and other emergent ones. This constitutes a factor that can favor the integration of new productive technologies in good conditions.

These new productive technologies constitute innovation and competitiveness vectors, in a short and medium term, even more. They constitute a strategic challenge for the company. So, it is fundamental for companies to be able to specify a requirement and to access to capable technical processes in order to obtain a coherent solution in a given technical-economical context. So, the knowledge related to validated solutions, the access to the knowledge of some experts from the company, a realistic perception of actual service capabilities constitute key factors for product development. This is why industrial companies are more and more interested in search engines that allow accessing to some dynamic knowledge from all over the World. This is possible thanks to new active cognitive agents [19] that are software allowing access to data but also giving the opportunity to send requests indispensable to more easily specify particular aspects. These new possibilities constitute a strategic opportunity for product and process integration in order to be able to very efficiently generate process planning for new product according to actualized industrial technologies and services. The cognitive agents are based on knowledge data models that link specification concept to manufacturing process planning. Thus, the most efficient solution today seems to be based on representative validated solutions, corresponding to realistic performance levels actualized depending on the technical capabilities of modeled processes.

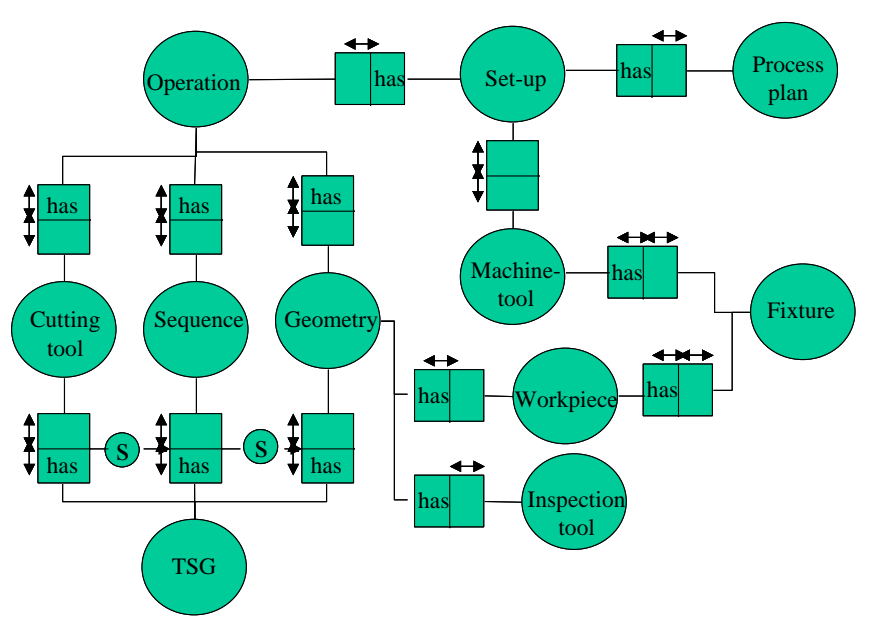

Figure 2 : fundamental structure of TSG concept [17]

This last idea has driven the research of A. Deglin [20]. The goal of such work was to memorize a database with case studies (successes and failures) related to typical rapid product development processes. These processes are mainly applicable to the manufacturing of prototype parts and products but is also concern to industrialization phase. The memorization and exploitation phases are based on an efficient man-machine interface and all the manipulated data are build using the proposed conceptual model. (Figure 3). This model represents the generic fundamental concepts that allow representing case studies and corresponding requirements. This corresponds to different models (user needs, requirement, technology and meta-technology, material, process, service provider company, state (numerical or physical). The user needs definition and the search for a solution are directly accessible via a specialized manmachine interface, based on KADVISER environment. The search engine is basically local for the first step of this approach and works based on case-based reasoning. If no valid solution is found, the system uses the ascendant generation algorithm based on the following principle: "from a final state corresponding to the user requirements, the algorithm selects all the technologies that are able to deliver a part in the final state". Then, for each initial state of each selected technology, the algorithm analyses the initial state of each selected technology. If it corresponds to the initial state given in the user requirements, it memorizes it as a possible solution. If not, it considers each of these intermediary states as the new final states to be obtained. Then it applies the same principle as longer as the initial state has been found for each branch of process or as longer as there is no technology able to deliver the intermediary state. Such branch is deleted and the solutions are delivered to the user. Each process solution is structured as a succession of states. The transition between two states is characterized by one or several technologies. Such sequence of states and technologies constitutes a process solution.

In the future, some efforts are going to be focused on a generalization of this approach for utilization based on cognitive agents connected to a request analyzer. A first experimentation has been to test the approach by the use of distributed databases accessible through Internet. The main difficulties are on one hand the dynamic aspect of knowledge (rapid and frequent changes, new technologies, new performances) and on the other hand the motivation of each expert to contribute to the formalization of his own knowledge according to generic concepts. This second aspect depends on the expert motivation to understand the concepts and to contribute to their evolution in order to improve the efficiency of the use of the memorized knowledge.

\subsection{Socio-technical aspect}

This aspect of complex systems and processes is not so much studied. But, there is an interest in such orientation because industrial environments have to be safe and secured, both for the technical dysfunctional behavior and for user safety. So, it is particularly important to integrate during the design stage some aspects related to the working place and environment and to potential risks due to technical choices for some particular function.

This is mainly why the CNRS (National Research Council for Science) has initiated the PROSPER program. In this context, the INRS (National Institute for Research and Safety) and a group of partners the CRAN was in, have decided to propose and develop an initiative based on the taking into account of the working situations during the design phase. More over, one of the goals was to give the user the possibility of evaluating the consequences of particular limit working conditions and their influence on the design of the production systems.

R. Hasan [21], in his PhD thesis, proposes an approach based on the working situation concept, and more particularly on the integration during design of socio- 
technical aspects and the interaction between the technical system and humans during the life-cycle of the production system. The already obtained results and the current display within the framework of a demonstrative software tool let expect possibilities of the approach, becoming widespread within the framework and a generic methodology in order to integrate the life-cycle of the system from the design stage. There are more particular aspects connected to the safety of people during their intervention on the technical system (normal use, degraded modes, change of production, maintenance, After-Sales Service Department, etc.). As the model of the figure 4 shows it, the concept of working situation allows setting up the relations between the technical system and the team of work, whatever the mode of intervention, the task, the tools and necessary consumables in execution of these tasks. One also finds there what can lead in an incident, even in an accident, through the concepts "environment", "dangerous event", "danger zone", "risk", "dangerous phenomenon". The dynamic aspect of the working situations (chain of the operations during tasks and use) appears on this model through the notion of operator of composition but is represented today using Petri's networks. From these last ones, it is in particular possible to obtain and to control the totality of the available procedures in use manuals.
It is clear that numerous research works will be necessary to characterize the most significant and/or influential parameters, with the aim of their evaluation compared in phase of design of the systems. This evaluation can doubtless, considering the current promising initiatives, be supported by tools and environments of the virtual reality favor in which one can immerse operators in their future working frame and put them in virtual contact with the system during the design stage.

This method could be also generalized in any phases of a product elaboration as well as in that of its life when the product is itself a system on whom people should intervene in a sure way during its life (concerning a car for example, during realization phases of the vehicle, during the production phases, during the use phase, during the maintenance operations, etc... of the vehicle itself). It is clear that all the links exist and that the true progress lies in their integration in support on an information system reagent (joinable in the various tools and environments of modeling and simulation) and coherent (based on realistic and evolutionary models taking into account experience feedback at the same time in simulation and during the life of the system). 


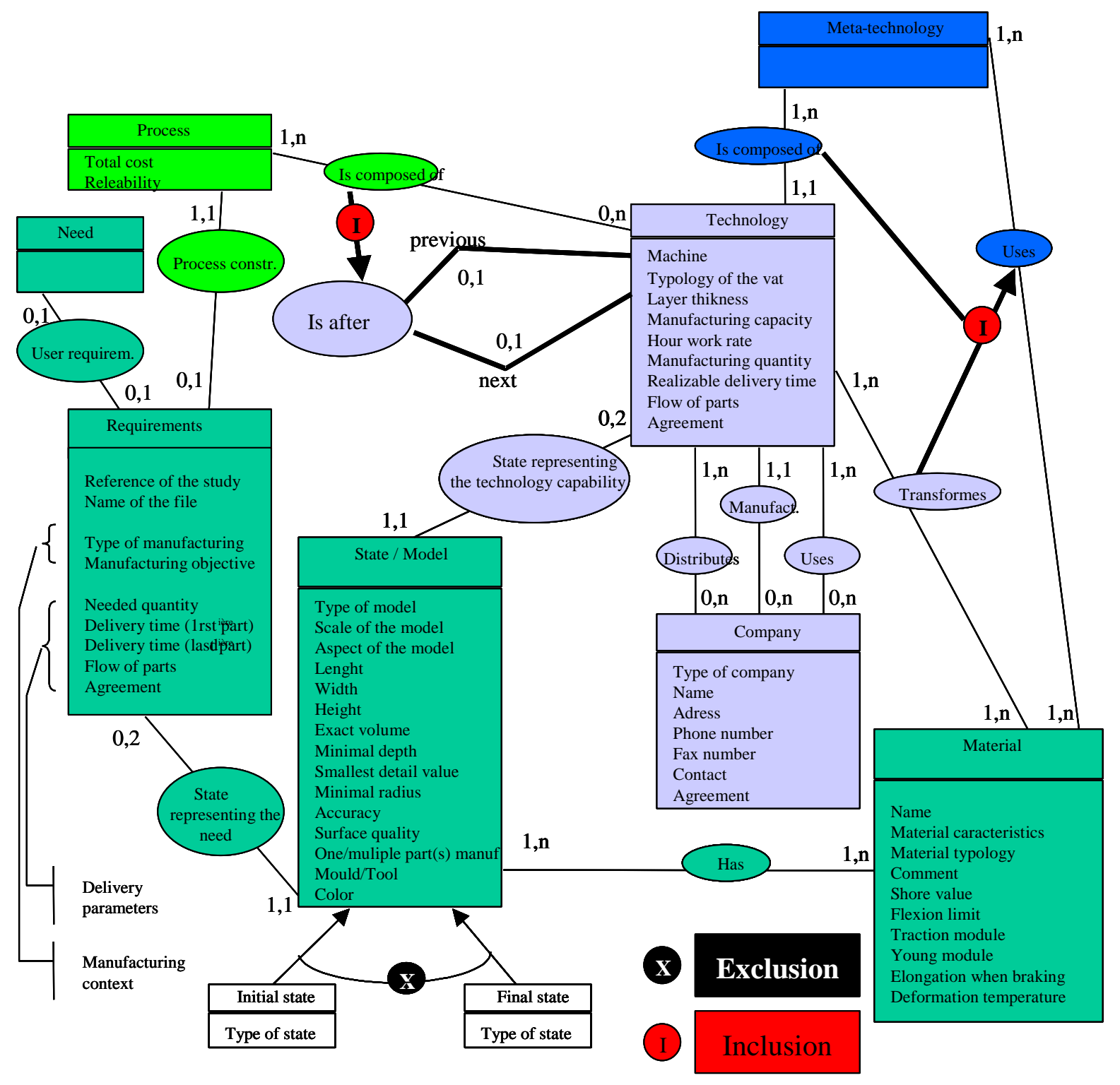

Figure 3 : data and working situation environment model [20]

\section{DESIGN PROCESS MODELS}

Elements presented previously are really useful only if the structured information can be managed, distributed, reused. Furthermore, the context of design is directed to a cooperative and distributed frame, because of the shared data and the multi-competence indispensable to the realization of products [22] [23] [24].

This context bases on basic elements allowing the representation and the memorization of the design process [25]. For some years, numerous initiatives have been concerning this problem of research in purposes of definition and integration of conceptual models of data and treatments, as well as in the definition and in the implementation of informational environments based on memorization of on-going and past project knowledge. It concerns as well elements relative to the product itself as its process of design and elaboration. It became so indispensable to better understand why, how, etc. each of the information is attached to the product. This is why numerous research works aim at memorizing what has to be during the life of the product. One speaks of history, of design intents, etc. [26].
Formalisms of process representation exist [27]. One can quote IDEF3, Petri's networks, GRAI networks, etc.; however, these elements do not constitute a solution in general approach necessary for the representation and for the management of the industrial knowledge. This is why basic elements, richer than those available in the classic approaches were proposed.

One can quote for example the works of A. Ouazzani who proposes a model based on the concepts of objective, action, argument and alternative [28]. This structure takes into account the resources to be used (human, physical, software, etc.) as well as the chain of the actions and the structure of the objectives. This model of process is connectable with the model of product through the notion of state. It is managed by specific actions told "management actions".

It is also necessary to mention the propositions of other laboratories in this subject, through the works of $A$. Saucier and C. Vargas, those of Y. Harani (integrating the notion of task, operator and of release mechanism) and finally those of P. Girard and B. Eynard [29], completing the basic tools of GRAI networks [30] in the specific frame of design. The characterization and the modeling of the processes stay problems on which the researchers keep 
on working, by trying in particular to widen the application field of the model in all the phases of the product life cycle [31].

\section{ORGANISATIONAL ASPECTS FOR INFORMATION ACCESS}

Because of the industrial globalization, the knowledge and the resources are more and more distributed in numerous sites. The necessary implication of the various competences as soon as possible during the life-cycle of products makes that one needs to reach in a fast way a distributed information, structured by knowledge for each skill, under coordinators' responsibility. These last ones have to master at the same time the technical processes, but also the process of development in design. This new mode of organization, e-design, e-engineering, emanufacturing [19] is set up mainly thanks to two catalyst factors that are the "net", the NTIC (New Technologies of Information and Communication) and the formalization of knowledge at the level of specific agents being organized in multi-agents network. These agents are based on models of product, technology, technical and design process such as described previously.

This organization in several levels opens possibilities for the integration of every new agent, but also represents all the difficulty of information search and expertise coordination with regard to a given technical, economic, social, etc. request. Even, numerous research pieces remain to investigate in this domain in strong expansion, the knowledge becoming more and more quickly obsolete.

It is also important to underline critical aspects for the communication intra and extra company. It is related in particular on the quality and the security of the information exchanges, of the traçability of the decisions, or the group dynamic communication during meetings, of works in project structures. It is related to an important part of researches for the scientific community and corresponds to a sensitive aspect of efficiency and the ability to react of companies.

\section{PROCESS: KEY CONCEPT FOR PERFORMANCE}

In the whole industrial context, the key factor is the profit, by a use of means economically realistic and by respecting the constraints of inconstancy due to the market. For that purpose, the knowledge of the costs and more generally the value transfers becomes essential during the phases of development then valuation of products.

So, it becomes necessary to be able as soon as possible to measure in different terms (technical, economic, social, of service, etc.), the consequences of a decision on the product (creation, evolution, standardization, diversification, etc.). Consequently, it becomes possible to structure all the processes inherent to the product life from elementary fundamental processes mastered in quality terms, cost and of time.

This approach also constitutes a base of evaluation for the company at the strategic, tactical and operational levels for the choice of fundamental orientations. Indeed, it is then possible to estimate a priori the consequences of such a choice, the opportunity of such other one by the measure of the impact of these decisions on the processes deployed for some product valorisation.

As it was shown first, it is already difficult to memorize enough technical knowledge to be able to suggest optimal industrial processes. This is on these bases that an approach of management by the industrial values becomes possible, by estimating the knowledge and the competence indispensable to deployment of a given process, by mastering the interactions between processes in order to be able to better estimate the consequences of a given modification, etc...

\section{SUMMARY}

Through this article, aspects connected to the problem of modelling of products and systems (in link with the processes and the process planning) as well as that of their processes were presented. The content is naturally not exhaustive, but representative of coherent tendencies that open perspectives of these research topics.

It is also question of elements related to the structure of information in link with the current organizations by competence or profession, what pulls information systems always more complexes based on the notion of cognitive agents

These systems will be more and more used for the assistance to decision process in all the levels of the company. This can be really realistic industrially only by the mastery of the strategic parameters characteristic of each of the elementary processes of the products life cycle .

The modelling and the assistance to the generation or the evaluation of the processes are one of the key factors products and industrial systems life-cycle mastery. These models and methods are more and more based on the knowledge of different kind, technical, economic, social, environmental, etc...

\section{REFERENCES (A FINALISER ET COMPLETER)}

[1] Bernard A., Contribution à la modélisation des produits et à l'intégration des technologies productrices dans un environnement multi-acteurs, Habilitation à Diriger des Recherches, Université Nancy-1, janvier 1996

[2] Bernard A., Modèles et approches pour la conception et la production intégrées, APII-JESA 34/2000, CPI'99, pp163-193

[3] Krause F.-L., Kimura F., KJellberg T., Lu S. C.-Y., Product modelling, Annals of the CIRP, Vol. 42/2/1993, pp 695-706

[4] Mony C., Un modèle d'intégration des fonctions Conception-Production dans l'ingénierie de produit Définition d'un système mécanique en base de données objet, Thèse de Doctorat, École Centrale Paris, 12 mai 1992

[5] SAUCIER A., Un modèle multi-vues du produit pour le développement et l'utilisation de systèmes d'aide à la conception en ingénierie mécanique, Thèse de Doctorat de l'ENS de Cachan, 1997

[6] VARGAS C., Un environnement pour la réalisation d'un système d'aide à la conception d'organes mécaniques, Revue Internationale de CFAO \& d'Informatique Graphique, Vol 10, N¹\&2, 1995, $\mathrm{p}$ 113

[7] SELLINI F., Contribution à la représentation et à la vérification de modèles de connaissances produit en ingénierie d'ensembles mécaniques, Thèse de Doctorat de l'Ecole Centrale Paris, mars 1999 
[8] Yvars P.A., Contribution à la représentation des connaissances en ingénierie de produits et de systèmes automatisés de production, Habilitation à Diriger des Recherches de l'INP Grenoble, spécialité Génie Industriel, janvier 2001

[9] Andreasen M. M., The theory of domains, Workshop on understanding function and function to form evolution, Cambridge University, 1991

[10] Grabowsky H., Lossack R. S., Weis C., Supporting the design process by an integrated knowledgebased design system, Advances in formal design methods for CAD, IFIP International Conference, Mexico, 1995

[11] HARANI Y., Une approche multi-modèles pour la capitalisation des connaissances dans le domaine de la conception, Thèse de Doctorat de I'INPG, 1997

[12] TICHKIEWITCH S., Specifications on integrated design methodology using a multiview product model, Engineering system design and analysis conference, ASME '96, Montpellier, 1996.

[13] Mawussı K., Modèle de représentation et de définition d'outillages de forme complexe. Application à la génération automatique de processus d'usinage, Thèse de Doctorat, ENS de Cachan, 20 janvier 1995

[14] Million O., De l'intégration des métiers par les données techniques vers la maîtrise de la modélisation conceptuelle : la méthode V.I.M. (View points Information Modelling) », Thèse de Doctorat de I'Université Henri Poincaré Nancy I, spécialité Production Automatisée, 21 Décembre 1998, Nancy

[15] Chambolle F., Un modèle de produit piloté par les processus d'élaboration - Application au secteur automobile dans l'environnement STEP, Thèse de Doctorat, École Centrale Paris, 29 avril 1999

[16] Villeneuve F., Génération ascendante d'un processus d'usinage. Proposition d'une formalisation de l'expertise. Application aux entités alésage, Thèse de Doctorat de l'Ecole Centrale de Paris, février 1990

[17] BEN YOUNES J., Modélisation des ressources en fabrication mécanique. Application au choix des outils coupants dans un environnement orienté objet, Thèse de Doctorat, École Centrale Paris, 19 janvier 1994

[18] Magnet-Canet S., Bernard A., Bocquet J.C., Un modèle d'intégration simultanée d'une technologie productrice : application à l'UTGV, $4^{\text {ème }}$ Colloque PRIMECA sur la Conception Mécanique Intégrée, La Plagne, avril 1995, pp 149-155

[19] Bernard A., Brissaud D., Improvement of design efficiency by using fabricability criteria through edesign cognitive agents, CIRP Design Seminar, Stockolm, juin 2001

[20] Deglin A., Bernard A., A knowledge-based environment for capitalisation and Computer-Aided Process Planning of rapid product development processes, Conférence CE (Concurrent Engineering) 2000, Lyon, juillet 2000, $\mathrm{N}^{\circ}$ ISBN : 158716-033-1, pp 650-659

[21] hasan R., Bernard A., Ciccotelli J., Martin P., Intégration de la sécurité dès la conception de systèmes de Production : modélisation de l'interaction homme- machine dans le fonctionnement du produit lors du processus de conception, IDMME'2000 $3^{\text {rd }}$ International
Conference on Integrated Design and Manufacturing in Mechanical Engineering, 16-19 mai, 2000. Montréal (Canada), N ISBN 2-553-00803-1, pp 186 (abstract, actes sur CDROM).

[22] SALAU I., La Conception Distribuée: Théorie et Méthodologie, Thèse de Doctorat, Université Henri Poincaré - NANCY I, DFD Automatique et Production Automatisée, 1995.

[23] BLANCO E., L'émergence du produit dans la conception distribuée vers de nouveaux modes de rationalisation dans la conception de Systèmes mécaniques, Thèse de Doctorat, Laboratoire Sols, Solides, Structures (3S) et CRISTO, 1998.

[24] Garro O., Conception distribuée et émergence, PRIMECA Université d'Automne, Nancy, 20 au 22 octobre 1999.

[25] sous la responsabilité de TOLLENAERE M., Conception de produits mécaniques, Edition HERMES, 1998.

[26] OuAzZANI A., Contrôle de cohérence et gestion de la sémantique dans le cycle de conception-production Application à la représentation du processus d'élaboration de produit, Thèse de Doctorat, École Centrale Paris, décembre 1999.

[27] VERNADAT F. B., Entreprise modelling and integration: principles and applications, Chapman \& Hall, London, 1996

[28] Ouazzani A., Bernard A., Bocquet J. C., Process modelling: a design history capture perspective, $2^{\text {nd }}$ International Conference Integrated Design and Manufacturing in Mechanical Engineering, Compiègne, mai 1998

[29] EYNARD B., Modélisation du produit et des activités de conception - Contribution à la conduite et à la traçabilité du processus d'ingénierie, Thèse de Doctorat de l'Université Bordeaux 1, 30 juin 1999

[30] Doumeingts G., GiRard P., Eynard B., GIM/GRAI integrated methodology for product development, Design for $\mathrm{X}$, Concurrent engineering imperatives, Chapman \& Hall, Londres, 1996

[31] BRISSAUD D., TICHKIEWITCH S., Product models for lifecycle, CIRP Annals, Vol 50/1/2001

[32] Krause, F.-L., Kimura, F., Kjellberg, T., Lu, S.C.-Y., 1993, Product Modeling, Annals of the CIRP, 42/2: 695-706.

[33 Brissaud, D., Tichkiewitch, S., 2001, Product models for life-cycle, Annals of the CIRP, 50/1:105-108.

[34] Fadier, E., Ciccotelli, J., 1998, Integrating safety into the design of industrial system: a general overview, $9^{\text {th }}$ IFAC Symposium on Information Control in Manufacturing, Nancy, pp. 233-239.

[35] Fadier, E., Ciccotelli, J., 1999, How to integrate safety in design: methods and models, Journal of Human Factors and Ergonomics in Manufacturing, Vol. 9 (4), John Wiley \& Sons, Inc. pp. 367-380.

[36] $\operatorname{Pr}$ EN 1010, 1997, European standard, definitive project. Safety requirements for the design and construction of printing and paper converting machines - Part 1: common requirements, European committee for standardization, Brussels.

[37] Jouffroy, D., Demor, S., Ciccotelli, J., Martin, P. 1999, An approach to integrate safety at the design stage of numerically controlled woodworking machines, Integrated Design and Manufacturing in Mechanical Engineering, Kluwer Academic publisher, pp. 643-650, ISBN 0-7923-6024-9. 
[38] Blaise J. C., Lhoste P., Ciccotelli J., 1999, Safety of machinery: integration of engineering, technical and normative views, European Safety and Reliability Conference, Schuëller \& Kafka (eds), Rotterdam, pp. 1411-1416, ISBN 90-5809-109-0.

[39] Choi B. K, Kim B. H., 2000, A human-centred virtual manufacturing system architecture for next generation manufacturing, CIRP Design Seminar, Haifa, Israel.

[40] Wang, H., Hammoud, H., Johnson, D. and Bakkar, J., 1997, A methodology for early front end structural design to meet safety requirements using CAE tools, ASME International Mechanical Engineering Congress and Exposition, November 16-21, Dallas, AMD Vol.225/BED Vol.38: 1-15.

[41] Garro, O., Salaü, I., Martin, P., 1995, Distributed design theory and methodology, Concurrent engineering. Vol. 3, $\mathrm{n}^{\circ} 1$, pp. 43-54.

[42] Sohlenius G., 1992, Concurrent engineering, Annals of the CIRP, 41/2:645-655.

[43] Harani Y., 1997, Generic model for the representation of design activity, XV INFORSID conference, Toulouse, France.

[44] Hasan, R., Ciccotelli, J., Bernard, A., Martin, P., 2000, Representation and evaluation of risks during the design phase of a complex system, ESREL 2000, Foresight and Precaution, Cottam, Harvey, Pape \& Tate (eds), Rotterdam, Netherlands, pp. 141-147, ISBN 90-5809-140-6.

[45] EN 292-1, 1991, European standard, safety of machinery, basic concepts, general principles of design - part 1: basic terminology, methodology, European committee for standardization, Brussels.

[46] EN 1050, 1997, European standard, safety of machinery - principles for risk assessment, European committee for standardization, Brussels.

[47] EN 614-1, 1995, European standard, safety of machinery, Ergonomic design principles - Part 1: terminology and general principles, European committee for standardization, Brussels.

[48] E 09-003, ENV 1070, 1993, European standard, safety of machinery, Terminology, European committee for standardization, Brussels. 